\title{
National Survey of Drug Information Centers Practices: Hospital Formulary System at Ministry of Health Hospital in Saudi Arabia
}

\author{
Yousef Ahmed Alomi ${ }^{*}$, Saeed Jamaan Alghamdi ${ }^{2}$ and Radi Abdullah Alattyh ${ }^{2}$
}

${ }^{1}$ Head, National Clinical Pharmacy and Pharmacy Practice, Head, Pharmacy R \& D Administration, Ministry of Health, Riyadh, Saudi Arabia

${ }^{2}$ General Administration of Pharmaceutical Care, Ministry of Health, Riyadh, Saudi Arabia

\begin{abstract}
Objective: To explore the National Survey of Drug Information Centers practice in Saudi Arabia: Hospital Formulary System at Ministry of Health Hospital.

Methods: It is a cross-sectional four months national survey of Drug Information Services at Ministry of Health It contained ten domains with 181 questions designed by the authors. It derived from Internal Pharmaceutical Federation (FIP), American Society of Health-System Pharmacists best practice guidelines. This survey distributed to forty hospital pharmacies that run drug information services. In this study, the domain Drug Monitoring and Patient Counseling System explored and analyzed. It consisted of eight questions about the written policy and procedure and application methods for Hospital Formulary System at $\mathrm{MOH}$ in the drug information centers. All analysis is done through survey monkey system.
\end{abstract}

Results: The survey distributed to 45 of hospitals, the response rate, was 40 (88.88\%) hospitals. The highest score of Hospital Formulary System at $\mathrm{MOH}$ was the Hospital Formulary should have the following information; generic name, dosage form, strength, therapeutic classification and prescribing information did not exist in $3(7.5 \%)$ hospitals while only $24(60 \%)$ of hospitals $100 \%$ applied the elements. The highest scores of DIC has a system for handling non-formulary drug requests was Non-formulary drug request form is available did not exist in $2(5 \%)$ hospitals while only $24(62.5 \%)$ of hospitals $100 \%$ applied the elements. The highest scores of DIC has a system for using formulary drugs for unapproved indications was the written multidisciplinary Internal policy and procedures for using formulary drugs for an unapproved indication and/or investigation did not exist in $7(17.5 \%)$ hospitals while only $18(45 \%)$ of hospitals $100 \%$ applied the elements.

Conclusion: There was an inadequate implementation of hospital drug formulary system in drug information centers practice. Establishment of educating and training of drug information pharmacist on the hospital drug formulary system with close monitoring will improve the network of drug information centers services at $\mathrm{MOH}$ hospitals in Kingdom of Saudi Arabia.

Keywords: Drug Information Centers; Hospital Formulary; Ministry of Health; Saudi Arabia

Abbreviations: KSA: Kingdom of Saudi Arabia; MOH: Ministry of Health; DIC: Drug Information Centers; IDS: Investigational Drug Services; PPS: Professional Publications Services

\section{Introduction}

Hospital Formulary is required as a part through hospital accreditation process of Saudi Board for Health Institution in the kingdom of Saudi Arabia and Joint Commission on hospital accreditation in the USA [1-3]. The full description on of Hospital Formulary established since several years ago by with American Society Health-System Pharmacist [4,5]. There are two types of Hospital Formulary open or closed formulary and $\mathrm{MOH}$ drug formulary as a closed one. There are several studies discussed the Hospital Formulary in Saudi Arabia but seldom find it as drug information activities or detail in depth of hospital drug formulary description. Also, an internal or external survey of network or group of drug information centers mentioned Hospital Formulary as part of drug information centers or pharmacy and therapeutics activities, or sometimes not mentioned at all, but such detail of Hospital Formulary description or system did not exist [6-8]. The authors are not familiar with local or international study for a description of hospital or drug formulary through a drug information centers survey. The objective of the survey to explore the national survey of drug information centers practice with emphasis on hospital drug formulary in Saudi Arabia.

\section{Methods}

It is a national survey of Drug Information Services at $\mathrm{MOH}$. It contained ten domains; Leadership and Practice Management, Medication Addition and Deletion System, Hospital Formulary System, Medication Safety System, Professional and Public Education. The Evidence-Based Medicine-Therapeutics Guidelines (EBMTG), Medication-Use Evaluation, Pharmacoeconomics System, Investigational Drug Services (IDS) and Professional Publications Services (PPPS) and Ethical and Legal Issue. It consisted of 181 questions designed by the authors. It drove from Internal Pharmaceutical Federation (FIP), American Society of Health-System Pharmacists best practice guidelines, the international standard of Joint Commission of Hospital Accreditation. In addition to the local standards of Saudi

*Corresponding author: Yousef Ahmed Alomi, Head, National Clinical Pharmacy and Pharmacy Practice, Head, Pharmacy R \& D Administration, Ministry of Health, P.O. BOX 100, Riyadh-11392, Saudi Arabia, Tel: +966504417712; E-mail: yalomi@gmail.com

Received: October 30, 2017; Accepted November 10, 2017; Published November 17, 2017

Citation: Alomi YA, Alghamdi SJ, Alattyh RA (2017) National Survey of Drug Information Centers Practices: Hospital Formulary System at Ministry of Health Hospital in Saudi Arabia. J Pharmacovigil 5: 247. doi:10.4172/2329-6887.1000247

Copyright: @ 2017 Alomi YA, et al. This is an open-access article distributed under the terms of the Creative Commons Attribution License, which permits unrestricted use, distribution, and reproduction in any medium, provided the original author and source are credited. 
center of health care accreditation and minimum standards of drug information centers in Saudi Arabia [2-3,9-11]. This survey distributed to forty-five hospital pharmacies that run drug information services. The information of hospitals services from extensive records of General Administration of Pharmaceutical Care. The study conducted in the year 2015. In this study, the domain Hospital Formulary System at $\mathrm{MOH}$ System explored and analyzed. It consisted sixteen questions about the written policy and procedure for Hospital Formulary System at $\mathrm{MOH}$ implementations. It included The Hospital Formulary established by Drug information centers (DIC) in collaboration with the Pharmacy and Therapeutics Committee. (DIC pharmacist is a member of P\&T Committee). The Hospital Formulary updated at least once in 2 years. The Hospital Formulary is available to all healthcare team. The Hospital Formulary should have the following information; generic name, dosage form, strength, therapeutic classification and prescribing information. The Hospital Formulary properly indexed using alphabetical indexing for generic named drugs. An approved abbreviation list for prescribing included in a separate section. The hospital formally has policy and procedure for prescribing, dispensing and administration regular medication. The Hospital Formulary has policy and procedure for prescribing, dispensing and administration of narcotics. The Hospital Formulary guides medication use: Medication utilization guidelines and/or restriction included in a separate section. Evidence of implementation by prescribers of the medication utilization guidelines. The medication dispensing as per medication hospital policy (dosing, duration, restriction, etc.). Written multidisciplinary IPP for handling non-formulary drugs including the defined period for drug procurement. Non-formulary drug request form is available. Clear evidence of proper handling of non-formulary drug request is available. Written multidisciplinary IPP for using formulary drugs for an unapproved indication and/or investigation. Application form for using the formulary drug for an unapproved Indication is available. Clear evidence of proper adherence to the IPP for using formulary drugs for an unapproved indication. The DIC actively participates in the several committees at the hospital. All analysis is done through survey monkey system.

\section{Results}

The survey distributed to 45 of hospitals, the response rate, was 40 (88.88\%) hospitals. The survey distributed to 45 of hospitals, the rate of reply, was $40(88.88 \%)$ hospitals. Of that $35 \%$ large hospitals, $37.5 \%$ medium size hospitals, $17.5 \%$ small size hospitals and $10 \%$ National and Regional Drug Information Centers. Of those, fifteen hospitals only accredited by CIBAHI and eight hospitals only accredited by Joint commission while none of all them accredited by ASHP or Canada. The majority of responders were Saudi 38 (95\%) and 28 (70\%) were male gender and $12(30 \%)$ were female as explored in Table 1 . The highest score of Hospital Formulary System at $\mathrm{MOH}$ was The Hospital Formulary should have the following information; generic name, dosage form, strength, therapeutic classification and prescribing information did not exist in 3 (7.5\%) hospitals while only $24(60 \%)$ of hospitals $100 \%$ applied the elements. Followed by the Hospital Formulary is appropriately indexed using alphabetical indexing for generic named drugs did not exist in $4(10 \%)$ hospitals while only $25(62.5 \%)$ of hospitals $100 \%$ applied the elements. An approved abbreviation list for prescribing included in a separate section did not exist in four (10\%) hospitals while only 25 (62.5\%) of hospitals, $100 \%$ applied the elements as explored in Table 2. The highest scores of DIC has a system for handling non-formulary drug requests was Non-formulary drug request form is available did not exist in 2 (5\%) hospitals while only 24 (62.5\%) of hospitals $100 \%$ applied the elements. The highest scores of DIC has a system for using formulary drugs for unapproved indications written multidisciplinary internally policy and procedures for using formulary drugs for an unapproved indication and/or investigation did not exist in 7 (17.5\%) hospitals, while only 18 (45\%) of hospitals $100 \%$ applied the elements as explored in Table 3. What the highest scores of drug information participated in the committee was The Drug Information Centers is an active participant

\begin{tabular}{|c|c|c|c|c|c|c|c|c|c|c|}
\hline \multicolumn{3}{|c|}{ Size, ownership and accreditation of respondents } & \multicolumn{2}{|c|}{ Nationality } & \multicolumn{2}{|c|}{ Sex } & \multicolumn{4}{|c|}{ Accreditation } \\
\hline Hospital size & $\begin{array}{l}\text { Number of } \\
\text { hospitals }\end{array}$ & Percentages & Saudi & Non-Saudi & Male & Female & CIBAHI & $\mathrm{JCl}$ & Canada & ASHP \\
\hline Small & - & - & - & - & - & - & - & - & - & - \\
\hline$<50$ & 1 & $2.50 \%$ & $1(2.5 \%)$ & $0(0 \%)$ & $1(2.5 \%)$ & $0(0 \%)$ & $0(0 \%)$ & $0(0 \%)$ & $0(0 \%)$ & $0(0 \%)$ \\
\hline $50-99$ & 6 & $15 \%$ & $6(15 \%)$ & $0(0 \%)$ & $6(15 \%)$ & $0(0 \%)$ & $0(0 \%)$ & $0(0 \%)$ & $0(0 \%)$ & $0(0 \%)$ \\
\hline \multicolumn{11}{|l|}{ Medium } \\
\hline $100-199$ & 7 & $17.50 \%$ & $7(17.5 \%)$ & $0(0 \%)$ & $6(15 \%)$ & $1(2.5 \%)$ & $0(0 \%)$ & $0(0 \%)$ & $0(0 \%)$ & $0(0 \%)$ \\
\hline $200-299$ & 8 & $20 \%$ & $7(17.5 \%)$ & $1(2.5 \%)$ & $5(12.5 \%)$ & $3(7.5 \%)$ & $5(25 \%)$ & $2(10 \%)$ & $0(0 \%)$ & $0(0 \%)$ \\
\hline \multicolumn{11}{|l|}{ Large } \\
\hline $300-399$ & 7 & $17.50 \%$ & $7(17.5 \%)$ & $0(0 \%)$ & $4(10 \%)$ & $3(7.5 \%)$ & $4(20 \%)$ & $2(10 \%)$ & $0(0 \%)$ & $0(0 \%)$ \\
\hline $400-599$ & 7 & $17.50 \%$ & $6(15 \%)$ & $1(2.5 \%)$ & $5(12.5 \%)$ & $2(5 \%)$ & $6(30 \%)$ & $4(20 \%)$ & $0(0 \%)$ & $0(0 \%)$ \\
\hline More than or equal 600 & 0 & $0 \%$ & $0(0 \%)$ & $0(0 \%)$ & $0(0 \%)$ & $0(0 \%)$ & $0(0 \%)$ & $0(0 \%)$ & $0(0 \%)$ & $0(0 \%)$ \\
\hline \multicolumn{11}{|l|}{ Very large } \\
\hline Medical Cities & 0 & $0 \%$ & $0(0 \%)$ & $0(0 \%)$ & $0(0 \%)$ & $0(0 \%)$ & $0(0 \%)$ & $0(0 \%)$ & $0(0 \%)$ & $0(0 \%)$ \\
\hline $\begin{array}{l}\text { National and Regional Drug } \\
\text { Information Centers }\end{array}$ & 4 & $10 \%$ & $4(10 \%)$ & $0(0 \%)$ & $1(2.5 \%)$ & $3(7.5 \%)$ & $0(0 \%)$ & $0(0 \%)$ & $0(0 \%)$ & $0(0 \%)$ \\
\hline Missing no-response & 0 & $0 \%$ & $0(0 \%)$ & $0(0 \%)$ & $0(0 \%)$ & $0(0 \%)$ & $20(50 \%)$ & $20(50 \%)$ & $20(50 \%)$ & $20(50 \%)$ \\
\hline Total respondents & 40 & $100 \%$ & $38(95 \%)$ & $2(5 \%)$ & $28(70 \%)$ & $12(30 \%)$ & $20(50 \%)$ & $20(50 \%)$ & $20(50 \%)$ & $20(50 \%)$ \\
\hline \multicolumn{11}{|l|}{ Ownership } \\
\hline MOH-Hospitals & 40 & $100 \%$ & & & & & & & & \\
\hline Non-MOH Hospitals & 0 & $0 \%$ & & & & & & & & \\
\hline Privates & 0 & $0 \%$ & & & & & & & & \\
\hline
\end{tabular}

Table 1: Size, ownership and accreditation of respondents. 
Citation: Alomi YA, Alghamdi SJ, Alattyh RA (2017) National Survey of Drug Information Centers Practices: Hospital Formulary System at Ministry of Health Hospital in Saudi Arabia. J Pharmacovigil 5: 247. doi:10.4172/2329-6887.1000247

Page 3 of 4

in the Pharmacy and Therapeutics Committee did not exist in five (12.5\%) hospitals while only $26(65 \%)$ of hospitals $100 \%$ applied the elements. The DIC actively participates in the Antibiotic Committee did not exist in seven (17.5\%) hospitals while only 20 (50\%) of hospitals $100 \%$ applied the elements as explored in Table 3.

\section{Discussion}

The hospital drug formulary is a list of medication that used in the hospital. The ministry of health Hospital Formulary is a list of medicines used for all hospital and primary care centers. The Hospital Formulary initially published before more than twenty years at the

\begin{tabular}{|c|c|c|c|c|c|c|c|}
\hline Answer options & 1 & 2 & 3 & 4 & 5 & $\begin{array}{c}\text { Rating } \\
\text { average }\end{array}$ & $\begin{array}{l}\text { Response } \\
\text { count }\end{array}$ \\
\hline $\begin{array}{l}\text { DIC establishes the Hospital Formulary in collaboration with the Pharmacy and } \\
\text { Therapeutics Committee. (DIC pharmacist is a member of P\&T committee) }\end{array}$ & 3 & 3 & 5 & 5 & 24 & 4.1 & 40 \\
\hline The Hospital Formulary updated at least once in 2 years. & 4 & 2 & 4 & 4 & 25 & 4.13 & 39 \\
\hline The Hospital Formulary is available to all healthcare team. & 4 & 2 & 6 & 2 & 25 & 4.08 & 39 \\
\hline \multicolumn{7}{|l|}{ Answered question } & 40 \\
\hline \multicolumn{7}{|l|}{ Skipped question } & 0 \\
\hline \multicolumn{8}{|l|}{ The structure of hospital drug formulary. } \\
\hline $\begin{array}{l}\text { The Hospital Formulary should have the following information; generic name, dosage } \\
\text { form, strength, therapeutic classification, and prescribing information. }\end{array}$ & 2 & 3 & 3 & 5 & 27 & 4.3 & 40 \\
\hline $\begin{array}{l}\text { The Hospital Formulary is appropriately indexed using alphabetical indexing for generic } \\
\text { named drugs. }\end{array}$ & 3 & 3 & 3 & 4 & 27 & 4.23 & 40 \\
\hline An approved abbreviation list for prescribing included in a separate section. & 2 & 5 & 2 & 6 & 24 & 4.15 & 39 \\
\hline $\begin{array}{l}\text { The hospital formally has Policy and Procedure for Prescribing, Dispensing, and } \\
\text { Administration Regular Medication. }\end{array}$ & 6 & 2 & 6 & 4 & 22 & 3.85 & 40 \\
\hline $\begin{array}{l}\text { The Hospital Formulary has Policy and Procedure for Prescribing, Dispensing, and } \\
\text { Administration of Narcotics. }\end{array}$ & 7 & 2 & 5 & 4 & 22 & 3.8 & 40 \\
\hline The Hospital Formulary provides guidance to medication use: & 2 & 3 & 6 & 6 & 23 & 4.13 & 40 \\
\hline Medication utilization guidelines and / or restriction are included in a separate section. & 6 & 4 & 6 & 6 & 18 & 3.65 & 40 \\
\hline Evidence of implementation by prescribers of the medication utilization guidelines. & 9 & 4 & 5 & 5 & 17 & 3.43 & 40 \\
\hline $\begin{array}{l}\text { Medication dispensing as per medication hospital policy (dosing, duration, restriction, } \\
\text { etc.). }\end{array}$ & 3 & 3 & 5 & 5 & 24 & 4.1 & 40 \\
\hline \multicolumn{7}{|l|}{ Answered question } & 40 \\
\hline \multicolumn{7}{|l|}{ Skipped question } & 0 \\
\hline \multicolumn{7}{|c|}{ 1: DIC is NOT applying the elements, 2 : DIC is applying $25 \%$ of the elements, $3:$ DIC is applying $50 \%$ of the elements } & \\
\hline \multicolumn{7}{|l|}{ 4: DIC is applying $75 \%$ of the elements, $5:$ DIC is applying $100 \%$ of the elements } & \\
\hline
\end{tabular}

Table 2: Updating of the hospital drug formulary system.

\begin{tabular}{|c|c|c|c|c|c|c|c|}
\hline Answer options & 1 & 2 & 3 & 4 & 5 & Rating average & Response count \\
\hline $\begin{array}{l}\text { Written multidisciplinary IPP for handling non-formulary drugs including the } \\
\text { defined time frame for drug procurement. }\end{array}$ & 4 & 4 & 8 & 5 & 19 & 3.78 & 40 \\
\hline Non-formulary drug request form is available. & 2 & 3 & 3 & 7 & 25 & 4.25 & 40 \\
\hline Clear evidence of proper handling of non-formulary drug request is available. & 3 & 3 & 7 & 9 & 18 & 3.9 & 40 \\
\hline \multicolumn{7}{|l|}{ Answered question } & 40 \\
\hline Skipped question & & & & & & & 0 \\
\hline \multicolumn{8}{|c|}{ The network of drug information centers and the system for using formulary drugs for unapproved indications. } \\
\hline $\begin{array}{l}\text { Written multidisciplinary IPP for using formulary drugs for an unapproved } \\
\text { indication and/or investigation. }\end{array}$ & 7 & 3 & 7 & 5 & 18 & 3.6 & 40 \\
\hline $\begin{array}{l}\text { Request form for using the formulary drug for an unapproved Indication is } \\
\text { available. }\end{array}$ & 7 & 3 & 7 & 4 & 18 & 3.59 & 39 \\
\hline $\begin{array}{l}\text { Clear evidence of proper adherence to the IPP for using formulary drugs for an } \\
\text { unapproved indication. }\end{array}$ & 6 & 5 & 8 & 6 & 15 & 3.48 & 40 \\
\hline \multicolumn{7}{|l|}{ Answered question } & 40 \\
\hline Skipped question & & & & & & & 0 \\
\hline \multicolumn{8}{|c|}{ The network of drug information centers and participated in all relevant hospital committees as evidenced by meeting minutes. } \\
\hline The DIC actively participates in the Pharmacy and Therapeutics Committee. & 5 & 0 & 4 & 5 & 26 & 4.18 & 40 \\
\hline The DIC actively participates in the Antibiotic Committee. & 7 & 3 & 4 & 6 & 20 & 3.73 & 40 \\
\hline The DIC actively participates in the Mortality and Morbidity Committee. & 17 & 4 & 6 & 5 & 8 & 2.58 & 40 \\
\hline The DIC actively participates in the Research and Ethical Committee. & 16 & 3 & 6 & 6 & 9 & 2.73 & 40 \\
\hline \multicolumn{7}{|l|}{ Answered question } & 40 \\
\hline \multicolumn{7}{|l|}{ Skipped question } & 0 \\
\hline \multicolumn{7}{|c|}{ 1: DIC is NOT applying the elements, 2 : DIC is applying $25 \%$ of the elements, $3:$ DIC is applying $50 \%$ of the elements } & \\
\hline \multicolumn{7}{|l|}{ 4: DIC is applying $75 \%$ of the elements, $5:$ DIC is applying $100 \%$ of the elements } & \\
\hline
\end{tabular}

Table 3: The network of drug information centers and the system for handling non-formulary drug requests. 
mid-1990s, it consisted of medication list with strength, dosage form and code number of $\mathrm{MOH}$ medical supply. The code number classified based on British National Formulary (BNF). The MOH formulary organized by a formulated committee with a membership of physicians, clinical pharmacists and hospital pharmacist from $\mathrm{MOH}$ organization and Monmouth government institutions. The committee responsible of approves addition, deletion and updating all $\mathrm{MOH}$ drug formulary. The $\mathrm{MOH}$ published the drug formulary several publications over past several years. The last edition the author was a member of the committee that switches the new name of Pharmacy and Therapeutic Committee. The $\mathrm{MOH}$ drug formulary consisted of drug list, dosage forms, strength and $\mathrm{MOH}$ code number. Also, the pharmacological classification medication index, medication alphabetical drug index, the policy and procedures of drug dispensing. The narcotic and control system for drug dispensing and distribution system in Saudi Arabia, attached as an appendix of the medication errors reporting system and requirements format, the adverse drug reaction reporting system and form and drug quality reporting system with necessary form. The authors investigated the Hospital Formulary system at drug information centers at $\mathrm{MOH}$ hospital. The finding showed more than half of the hospital had some element of drug formulary system which less than old study by Gallo and Wertheimer [12] and new two studies done by Rosenberg conducted in 2004 and 2009 [6-7]. The findings expected due to the profound experiences of $\mathrm{MOH}$ drug information centers and lower human resources with lower qualification as compared to them. The non-drug formulary handling system finding was better than old study by Gallo and Wertheimer [12] and that's because the system well developed at $\mathrm{MOH}$ hospitals for any medication out of formulary and purchasing and budget consumed. Other detail difficult to compare with studies because it did not mention them. The hospital drug formulary should revise and update the system in such detail to improve the services of drug information centers at $\mathrm{MOH}$ hospitals $[13,14]$.

\section{Conclusion}

Although it was the first study conducted in Saudi Arabia, Gulf and Middle East countries, there was an inadequate implementation of hospital drug formulary system in drug information centers practice. Targeting to An educating and training of drug information pharmacist on the hospital drug formulary system and implementation of this section improves the implementation the services. It raises the services levels up to the international and national accreditation standards of a network of drug information services, improves medication management and usage and avoids the unnecessary additional cost.

\section{References}

1. ASHP guidelines for hospital formularies. Am J Hosp Pharm 35: 326-328.

2. Medication Management (MM) (2015) In: National Hospital Standards. 2nd (edn) Saudi Central Board for Accreditation of Healthcare Institutions. 194-211.

3. Comprehensive Accreditation Manuals. Joint Commission Resources.

4. The American Society of Health-System Pharmacists (2009) Statement on the Pharmacy and Therapeutics Committee and the Formulary System. Am J Heal Pharm 65: 2384-2386.

5. Chase KA (2008) Medication Management Use. In: Introduction to Hospital and Heath-System Pharmacy Practice. 59-80.

6. Rosenberg JM, Koumis T, Nathan JP, Cicero LA, McGuire H (2004) Current status of pharmacist-operated drug information centers in the United States. Am J Heal Pharm 61:2023-2032.

7. Rosenberg JM, Schilit S, Nathan JP, Zerilli T, Mcguire H (2009) Update on the status of 89 drug information centers in the United States. Am J Heal Pharm 66: 1718-1722.

8. Alamri SA, Ali R, Jaizani A, Naqvi AA, Safer M, Ghamdi MSA (2017) Assessment of drug information service in public and private sector tertiary care hospitals in the eastern province of saudi arabia. Pharmacy (Basel) 5 pii: E37.

9. Vernon G, Dvorkin L, Vidotti CCF, Woods D (2005) Requirements for Drug Information Centres. FIP Pharmacy Information Section.

10. Ghaibi S, Ipema H, Gabay M (2015) ASHP guideline on the pharmacist's role in providing drug information. Am J Health Syst Pharm 72: 573-577.

11. Ministry of Health GPCD (2014) Minimum standard of Drug Information Center in KSA. Ministry of Health, Saudi Arabia.

12. Gallo GR, Wertheimer Al (1985) An international survey of drug information centers. Drug Inf J 19: 57-61.

13. Brummel A, Carlson AM (2016) Comprehensive Medication Management and Medication Adherence for Chronic Conditions. J Manag Care Spec Pharm 22 56-62.

14. Alamri SA, Al Jaizani RA, Naqvi AA, Al Ghamdi MS (2017) Assessment of drug information service in public and private sector tertiary care hospitals in the eastern province of saudi arabia. Pharmacy 5: 37. 